\title{
Derechos: Warning Based Words Matter
}

\section{Dean D Davison*}

Senior Meteorologist, The Weather Pros, NY, USA

*Corresponding author: Dean D Davison, Senior Meteorologist, The Weather Pros, NY, USA, Tel: 540-521-8625; E-mail: dean@theweatherpros.com

Received date: Mar 10, 2017; Accepted date: Mar 25, 2017; Published date: Mar 28, 2017

Copyright: ( 2017 Davison DD. This is an open-access article distributed under the terms of the Creative Commons Attribution License, which permits unrestricted use, distribution, and reproduction in any medium, provided the original author and source are credited.

Citation: Davison DD (2017) Derechos: Warning Based Words Matter. J Climatol Weather Forecasting 5: 200. doi:10.4172/2332-2594.1000200

\section{Short Communication}

In 2012, A Derechos formed in the afternoon of a June 29, 2012 and lasted into the morning of June 30 2012. This complex started in Iowa and moved across IL, IN, OH, PA, MD, WV, VA, NJ, and DE. Winds over $90 \mathrm{mph}$ occurred on multiple locations in this Derecho as it moved across multiple states. Trees and powerlines as well as structures were being taken out and damaged. A $91 \mathrm{mph}$ wind occurred in Fort Wayne.IN. A basic severe thunderstorm watch was issued non pds. As the line moved it was killing people 28 to be exact. Scattered structural damage also occurred along the path of the Derechos, from both falling trees and the winds themselves. Some of the damage included siding torn off houses, roofs removed from houses, businesses and apartment buildings, mobile homes heavily damaged, barns and garages destroyed and airplanes flipped. Why was there not better warning and a heightened alert? Would that change how people reacted? Below we will discuss how this effected people and the study on how changing words could have made people react different. This will also go over the psychological thoughts of people in this survey. This survey was conducted by me to learn and hope to improve the strength of warnings.

Just after the Derecho moved thru and I was in Lynchburg VA looking over damage I saw many people in the 100-degree weather outside. I thought to myself why not question these people and see how they reacted to the warning then a second question that if certain words were used in the warnings would they change the way they took the warning. People were very happy to take this survey and I took 500 people and they were all given the same questions.
I chose to do this right after the system as it was fresh in the minds of people. Some people who took this survey answered the questions with passion. People did not understand why it was worse than a regular severe thunderstorm. This was taken via paper survey that I had composed to ask the questions to get the information. Some of the thought processes in the actual survey where we didn't have adequate warning and for those whom didn't want to change their views it was sated "If it's our time to go it's our time" God makes the decisions not me. You must understand there are so true bible based people in Lynchburg where one of the biggest christen university is, Liberty University. To more panic was shown not knowing the force of the storms coming then freaking the people out. To this day, a severe thunderstorm with wind brings comparison.

First on the list was how people took the warning. Out of 500 people 128 people took it more serious than a normal severe thunderstorm warning. Eighteen people took it as it was a tornado and were very situationally aware. Three Hundred and fifty-four people. Took it as a normal severe thunderstorm warning doing nothing different or not taking adequate cover.

So, in the second form I added a few key words that are stronger than a normal warning. One is May kill you If outside. Another was cause catastrophic power loss for weeks. The third was may cause damage of a tornado. After adding that to the wording many people said they would have taken it much. 